\title{
THE 3D DOCUMENTATION OF PROJECTED WOODEN WINDOWS (THE ROSHANS) IN THE OLD CITY OF JEDDAH (SAUDI ARABIA) USING IMAGE-BASED TECHNIQUES
}

\author{
A. ALITANY ${ }^{\mathrm{a}, *}$, E. REDONDO ${ }^{\mathrm{a}}$, A. ADAS $^{\mathrm{b}}$ \\ ${ }^{a}$ Dept. EGAI, Expresió Gráfica Arquitectónica I ETS Arquitectura Barcelona-UPC, Barcelona, Spain \\ ayman.arch@gmail.com \\ ernesto.redondo@upc.edu \\ ${ }^{\mathrm{b}}$ Faculty of Environmental Design, King Abdul Aziz University- KAU, Jeddah, Saudi Arabia \\ aaadas@kau.edu.sa
}

KEY WORDS: Image-based 3D modelling, Architectural Heritage Documentation, The Roshan, The Historical city of Jeddah

\begin{abstract}
:
The Roshan represents one of the most characteristic aspects of traditional architecture in Hejaz (Saudi Arabia) and a frequent feature in most of the Historical Jeddah's heritage buildings. The old city has witnessed continued degradation recently, which has caused the loss its traditional architecture and hundreds of these projected wooden windows. Documentation is a major step towards heritage preservation, whether threatened by man-made or natural factors. However, due to the absence of specialists and experts an architectural database of the Roshans does not exist. Surveying these architectural elements is a very laborious and difficult process when using conventional methodologies including the laser sensors approach mainly due to the onsite limitations. Establishing an architectural database of the Roshans is the main objective in this research paper, based on the continuous development of data capture and modelling methodologies that allows the accurate recording of even the most complex and intricate details and patterns which are typically found in Roshans. Recent advances in image based techniques (digital close-range photogrammetry and computer vision) such as the semi-automated solutions of Dense Stereo Matching (DSM) and 3D modelling software has offered an accurate, inexpensive and practical solution to surveying, documenting and reconstructing these architectural heritage features. In this paper the application of these methods is tested and evaluated on the Roshans in the old city of Jeddah.
\end{abstract}

\section{INTRODUCTION}

The Roshan is clearly the most visual element that is characteristic of most, if not all, of historical Jeddah's heritage buildings. Throughout the years the historical city of Jeddah has been subject to continued degradation with many aspects of its architectural heritage being threatened by man-made and natural factors. Indeed, during the last fifty years Jeddah has lost many of its historical buildings as well as many of the valuable Roshan's elements. These features are slowly disappearing without any records, primarily due to the absence of specialists and experts in architectural documentation and surveying.

Nowadays, these wooden elements remain in numerous buildings hanging on the facades. Thus, documentation is a major step towards the preservation of these wooden elements. However, surveying these architectural elements is very laborious and presents many practical and logistical problems when using conventional measurement such as 3D laser sensors methods, due to site obstacles and the complexity of Roshans; indeed, these features are scattered on various building with variety in shapes and levels which makes traditional methods of surveying incredibly difficult (Figure 1).
In recent history, 3D modelling techniques have been rapidly advancing with part of the focus on developing these technologies for applications such as architectural heritage documentation. The ability to capture accurate details and the degree of automation vary widely from one approach to another. For example, image-based modelling techniques have been successfully used for many years (Remondino and El-Hakim, 2006). Photogrammetry and computer vision are generally used to capture basic shapes and details from high-resolution digital images. Recent advances technology have allowed semiautomated and automated solutions based on Dense Stereo Matching (DSM) (Furukawa and Ponce, 2007; Hirschmuller, 2008) and 3D modelling software's commercially availability offer accurate solution to obtain 3D point clouds and textured models. This methodology provides a cheap and practical solution to surveying, allowing a quick and cost effective method in documenting and reconstructing the architectural heritage elements which has enjoyed many impressive results in the literature (Remondino and Menna, 2008; Hullo et al., 2009; Alby et al., 2009;). Using these approaches in order to create a $3 \mathrm{D}$ database of architectural heritage is the main objective in this research work. Thus, we propose an appropriate

\footnotetext{
* Corresponding author.
} 
methodology developed from the image-based 3D modelling techniques that allow accurate, fast, cost effective means with a high level of mobility and flexibility for recording all complex and intricate details and patterns which are typically found in Roshan and other historically important wooden features.

To these ends the following paper is divided into six sections. First, section two provides some general information about the historical city of Jeddah, including the provisions already in place to preserve buildings of historic value and some of the problems that have contributed to the degradation of these buildings. This is followed by section three which discusses the structural components and description of the typical Roshan found in the historical city of Jeddah. Section four then turns to the surveying methodology in the application of digital closerange photogrammetry and DSM technology which were tested and evaluated on several Roshans and their ornamented parts. Section five comes in the form of an accuracy report on the project and the methodology employed where Photomodeler Scanner $^{\mathcal{O}}\left(\mathrm{PMS}^{\odot}\right)$ and Rhinoceros ${ }^{\mathcal{O}}$ software for $3 \mathrm{D}$ modelling process were considered. $\mathrm{PMS}^{\odot}$ is a program that helps extract measurement and from images. By using a digital camera as an input device, the software allows to capture accurate detail in short time. Section six provides a conclusion on this research project.

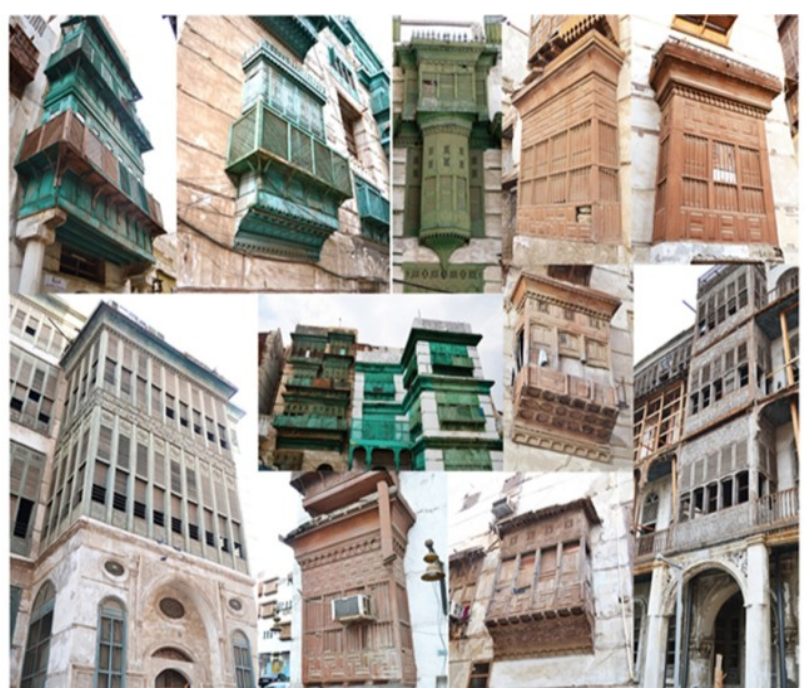

Figure1. Examples of different types of Roshans in the Historical City of Jeddah.

\section{THE HISTORICAL CITY OF JEDDAH}

The Historical City of Jeddah (Al-Balad [the village]) is located on the eastern shore of the Red Sea, almost halfway among the northern and southern borders of the Kingdom of Saudi Arabia. Jeddah is classified as one of the most important historical sites in the Middle East in Hejaz region in Saudi Arabia as it is still preserves a coherent unity and a specific urban character. Jeddah's city centre still contains the multi-story houses built of coral stone and plaster adorned with teak doorways and projected latticework windows that typified the architecture in ports on both sides of the Red Sea until the 19th century. The Old City of Jeddah is characterized by a dense urban pattern and narrow alleys with compact blocks exploiting the largest part of the plots covering an area of about $1 \mathrm{~km}^{2}$. Most of the structures making up the dense city are less than 200 years old and generally consist of three and four-storey houses. The National Antiquities Regulation has been in place since 1980 and guarantees state protection of buildings classified as historically valuable. The work of Robert Matthew constitutes the basis of the current building regulations enforced in the old city which includes a complete listing of the old city houses and a three level tier classification of the traditional buildings based on their architectural and historic significance (Matthew, 1972). Class A buildings were deemed of national significance, class B of regional and class $\mathrm{C}$ has having local significance. Despite this classification system the regulation has apparently failed to protect many of the historic buildings in Jeddah. Out of 557 historically important buildings (Figure 2), now only 312 remain including many tower houses with over 1500 Roshans which are likely to disappear if the current neglect continues. This problem is exacerbated with the challenges presented by the harsh Red Sea weather and general passage of time.

\section{THE ROSHAN}

\subsection{Description}

The Roshan characterizes traditional architecture in Hejaz, in western Saudi Arabia, and considered as its emblem, the Roshan is clearly the most visual element that makes up most if not all Historical Jeddah's heritage buildings. The term Roshan can be traced as far back as $1100 \mathrm{AD}$ and in North Africa, Egypt and Yemen has come to be known as Mashrabiya. The Roshan is a large projecting three-sided wooden structure on a building's façade, with a recognizable latticed component. A typical Roshan is about 2.4-2.8 $\mathrm{m}$ in width, $0.4-0.6 \mathrm{~m}$ in depth, and $2.7-3.5 \mathrm{~m}$ in height although this can vary considerably.

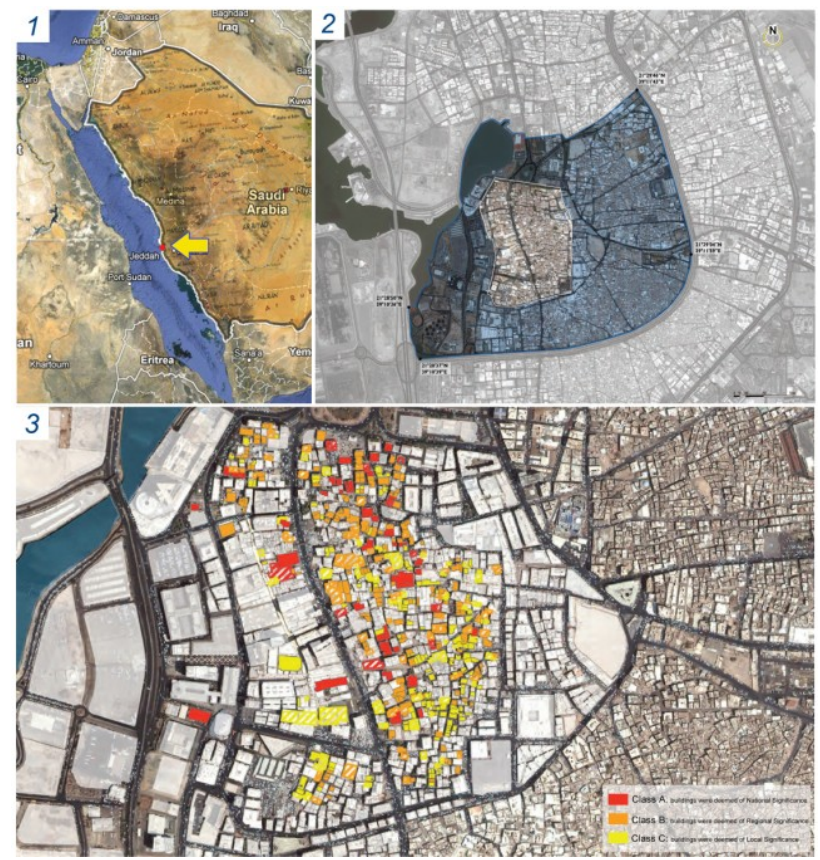

Figure 2. 1) The location of Jeddah city in Saudi Arabia, 2) satellite image showing the limits of the historical city of Jeddah property and buffer zone, 3) Robert Matthew's classification of Historical buildings.

However, due to the weight of the wood used, they are constrained to a projection depth of an average of $0.6 \mathrm{~m}$, which is their most constant dimension. On the inside, combing the projection depth with the wall thickness, the Roshan is usually wide enough for two people to sleep, about $1.2-1.4 \mathrm{~m}$, and large enough for a person to stand at around $2.4-2.7 \mathrm{~m}$ internal height (Jomah, 1992; Angawi,1995). 


\subsection{Types and parts}

The Roshan appear in many shapes and sizes with different levels of heights on the façades of historical buildings. Among the different types there are many similarities and differences, depending on the variance in the Roshans assembled parts. Some of parts are standard in all Roshans while others elements are additional and optional making one Roshan different from another. However at the same time each part has a function, and its presence or absence can affect the Roshans performance. Given the huge diversity in the types and features of Roshans we propose a new classification method; specifically focusing on the annotated shapes and parts for these architectural wooden structures in the Old City of Jeddah according to the matrix of three dimensions criteria: 1) shape complexity; 2) layout arrangement; and 3) height level on the façade. Despite this variation, all types of Roshans are ultimately composed out of similar main componants so the absence or presence of other secondary parts distinguishes the Roshan's type. Many parts can be observed in a typical Roshan, and can generally can be divided into three main structural assembled elements, from bottom to top, into" Base" the lower part, "Body" the middle, and "Head" the upper part (Figure 3). These three parts can be simple or complex.

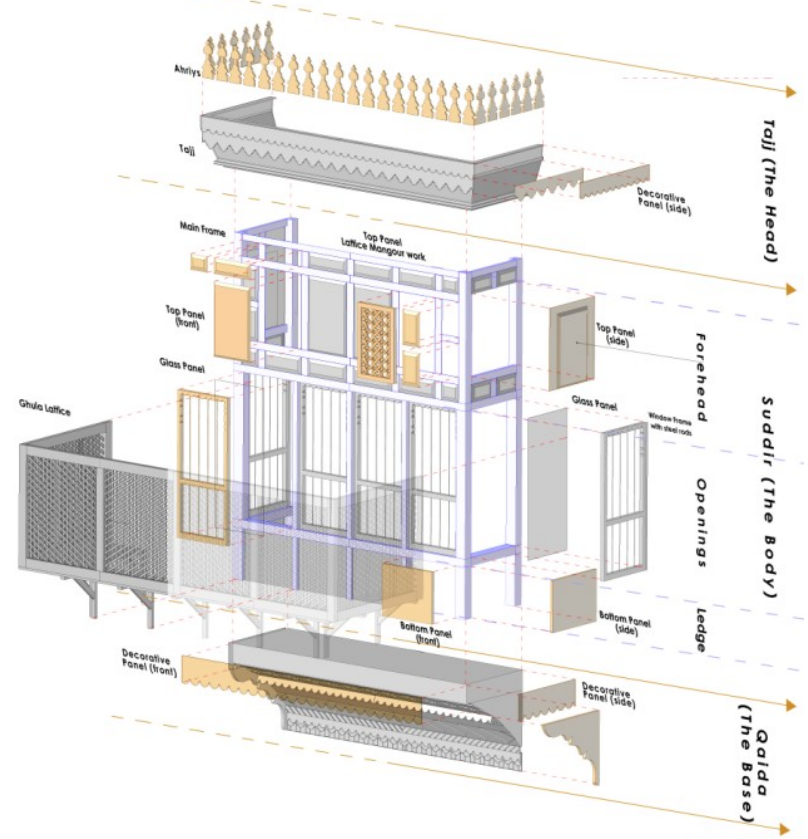

Figure 3.Exploded view of the Roshan's parts and components.

\section{SURVEYING METHODOLOGY}

\subsection{Description}

In the initial stages of this project, two aspects were considered: first, the selection of a suitable method that best fits according to current state of art of image-based approaches and 3D modelling techniques in the existing architectural heritage documentation; second, appreciating the variety and complexity of the Roshan element. Thus we divided the surveying and modelling procedures into three scales: 1) Main structural parts: base, body and head that defined the entire mass. On this scale we used the semi-automated digital close-range photogrammetry method using a calibrated camera; 2) Complex detailed sub-components, which are related to the main parts, adorned and ornamented, using DSM (Dense Stereo Matching approach). These two procedures are offered in several commercial solutions. In this project, the Photomodeler Scanner ${ }^{\mathcal{O}}\left(\mathrm{PMS}^{\mathcal{O}}\right)$ software has been tested on the Roshans and is inexpensive, flexible and an accurate solution to get textured models and 3D point clouds; 3) Analysis, interpretation and combining parts using Rhinoceros ${ }^{\odot} 3 \mathrm{D}$ modelling software. In (Figure 4) the full process is described in schematic form.

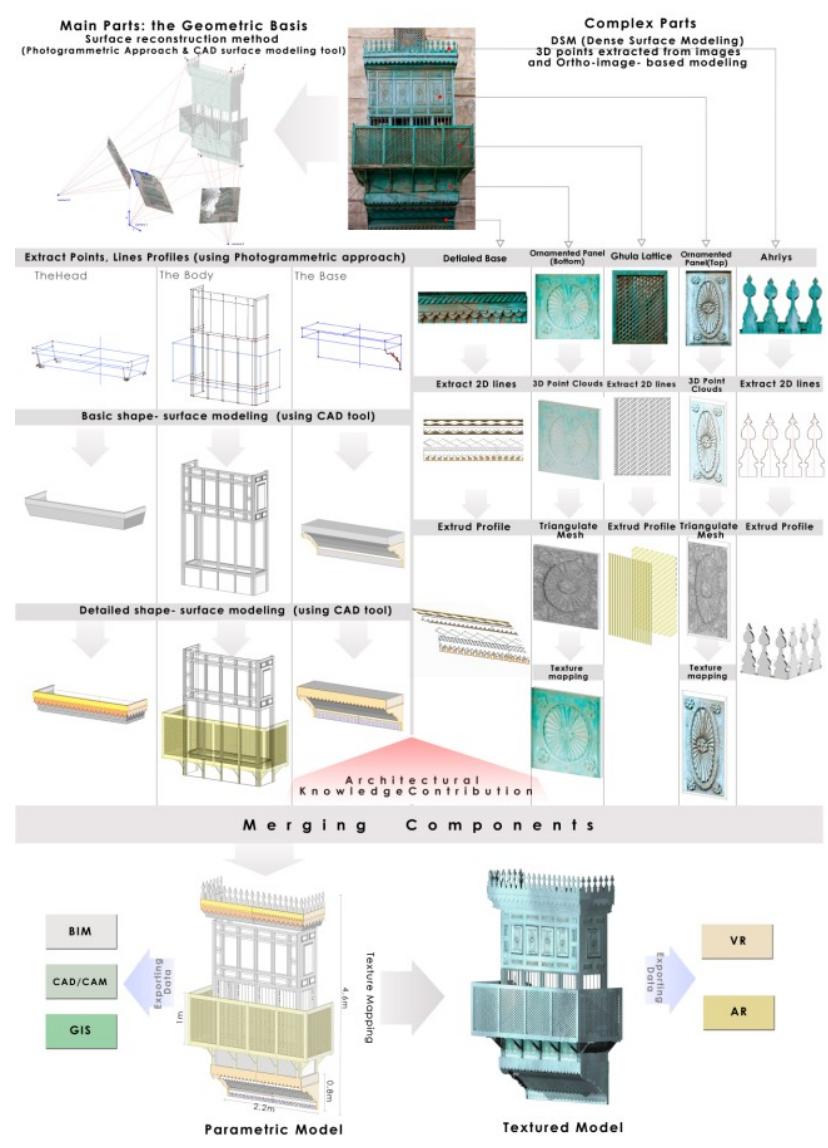

Figure 4. Schematic diagram of surveying and modelling process.

Furthermore it is important to note that the surveying and modelling methods were based on the Roshans construction and assembling process, and architectural knowledge. During that general strategy, in several cases, we adopted equipments and techniques assistance: scissor left $(15 \mathrm{~m}$ height), sketches drawings and manual reference measurements. In addition, the process was reinforced by the geo-referencing for control points supporting images orientation and data acquisition process.

\subsection{Main Structural Parts}

We started by detecting the control points that form the structured parts of the Roshans and defined the relevant profiles extracted in semi-automatic or manually method by using Photomodeler Scanner ${ }^{\mathcal{O}}\left(\mathrm{PMS}^{\mathcal{O}}\right)$, a digital photogrammetry application. A points-based approach from 3-8 images covered the Roshan total shape and we followed the $3 \times 3$ CIPA rules. NIKON D3100 digital camera with focal lengths 18 and $35 \mathrm{~mm}$ were used in this research and had to be calibrated through reference to a calibration grid. All important control points on the Roshan had to appear in at least every three adjacent images 
taken. $\mathrm{PMS}^{\odot}$ required reference points marked in two or more of these images. In addition, the process was reinforced by using control points that supported image data acquisition and the orientation process; especially for scaling or in identifying the thickness of interior components of the Roshan. The combination of this data allowed the definition of profiles from the generated baselines from edges and the surfaces while allowing classification of the relative importance of the parts in these wooden elements.

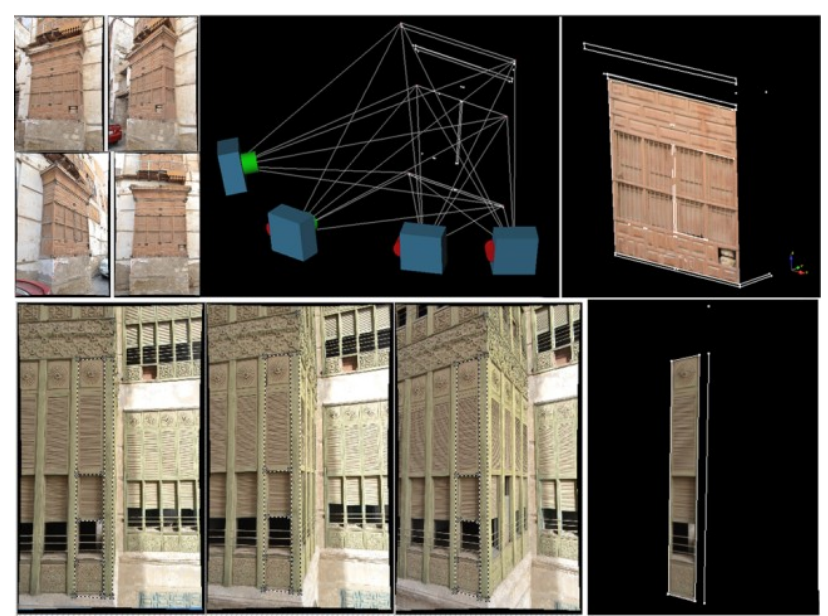

Figure 5. Extraction process of points and edges in $\mathrm{PMS}^{\complement}$.

\subsection{Complex parts}

We used the DSM as a set of tools for extracting and manipulating a dense pattern of point clouds from photographs, which allows accurate measurement for ornamented objects while also being flexible and cheap compared to 3D laser scanner technology. PMS ${ }^{\odot}$ is capable of performing modelling and measuring tasks with the additional attribute to scan photo pairs to produce point clouds and mesh surfaces. Our DSM experiment is presented by describing a complete process from acquisition images until the final result. First of all, before the capturing images, to obtain a high level of accuracy, the camera calibration process was required. By photographing the calibration sheet, the camera defects can be managed and calculated through $\mathrm{PMS}^{\odot}$. The accuracy of the final results is related to the corrected basic parameters of the camera (focal length, sensor resolution, optical distortions, point coordinates). Once the calibration process was complete, we started to capture a pair of images of the ornamented objects with low angle; in this case good skills for photographs were needed. In some cases, to ensure a total coverage of the object, we used multi stereo pairs in order to model the entire structure (Figure 6). It is recommended to use the camera with a fixed (nonzoom) lens in good lighting conditions while using coded targets to speed up the DMS process. In addition these codes can be used as reference measurements which assist the orientation process and project validity. Moreover, it is essential to take additional sets in order to avoid errors during the acquisition process. In surveyed details we used the NIKON D3100 digital camera with focal lengths $18 \mathrm{~mm}$. Thereafter, in $\mathrm{PMS}^{\odot}$, we applied the inverse distortion equations on selected set of images. Then, the idealized images are prepared for matching. Manually, we marked spread points on the object such as the main edges and corners and the coded targets were recognized in automatic mode. Subsequently, matching was processed by adjusting a number of parameters. As result, the
3D point cloud is created. The best stereo pairs were chosen to apply DSM separately for each part. After the post processing step, we merged all the point clouds in the merge option. Then we were able to adjust our model using triangle decimation, filling holes in the mesh, smoothing mesh and removing useless points. Finally, the $3 \mathrm{D}$ results can be exported into many standard 3D formats (DXF, 3Ds, IGS) as well as 2D orthoimages. The duration of a single stereo pair process from data acquisition to exporting 3D result require less than one hour using PC or laptops with the creation of a 3D model not exceed 10 to 15 minutes for processing.
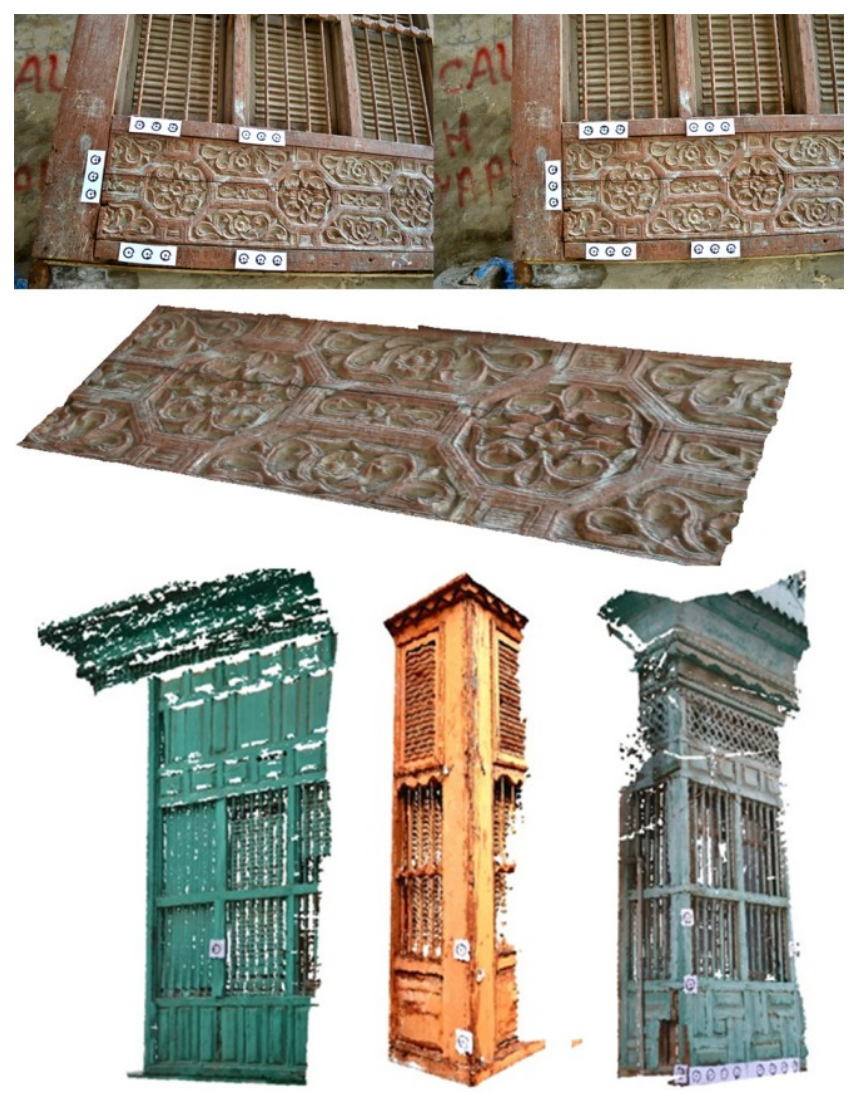

Figure 6. The results in $\mathrm{PMS}^{\odot}$ from one and multi stereo pairs.

\subsection{D Surface Modelling and merging process}

The modelling system and management of the $3 \mathrm{D}$ extracted data from images as well as their interpretation of this data is performed with Rhinoceros ${ }^{\odot}$, an educational application allows the generation of complex surfaces. This edits and translates NURBS (Non-Uniform Rational B -Splines) curves, surfaces, and solids with no limits regarding complexity, degree or size. The software also supports polygon modelling, meshes and point clouds that allow the creation of NURBS surfaces for ornamented pats. This method is relatively easy to use and works with many formats, which is useful for the merging and integration of the different parts of the model. Accurate positions of the Roshans corners points and its major structural elements were defined based on the generated 3D data of the control points and targets in $\mathrm{PMS}^{\odot}$ with topographic support and measured dimensions. In this way different surfaces were generated. Merging partial components was also performed on Rhinoceros ${ }^{\mathcal{O}}$ due to the various advantages outlined above and based on the criteria and standards Roshan composition. This manual process is not easy because we had to combine different 
types of 3D models and images with different resolutions. This requires removing the redundant parts of various objects and merging models based on initial reference points, which then exports the results to a visual simulation application that allows the appearance of the Roshan model to be shown.
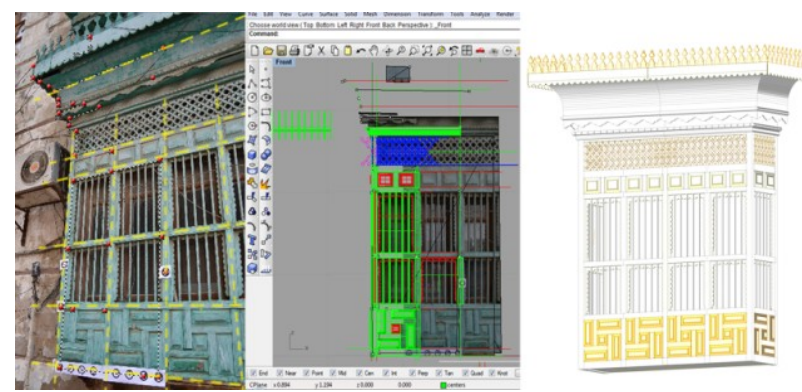

Figure 7. Modelling process in Rhinoceoros ${ }^{\odot}$ software.

\section{ACCURACY ASSESSMENT}

Generally, in order to ensure a good accuracy, we used the manual measurements and the distance between coded targets on site as reference points for scaling and orientation for the main structural shapes and ornamented details. In $\mathrm{PMS}^{\odot}$, the quality of the acquired models were assessed by the residual values between the image coordinates marked on the images and the image coordinates calculated through the calibration of the cameras . According to the guidelines of $\mathrm{PMS}^{\odot}$, for an accurate photogrammetric project the RMS residual value should be less than 1.0 pixel. In reviewing the acquisition process and analyzing several generated models of Roshans in $\mathrm{PMS}^{\odot}$, data was semi-automatically interpreted to define the outlines and edges. In Figure 8, the table shows the RMS residual values which represent the accuracy achieved in one of our examples. The largest acceptable value is 0.4 pixels and manually we defined an error at $0.8 \mathrm{~mm}$. By using DSM in ornamental motifs, the generated mesh surface has 466,912 vertices and 932,643 polygons (Figure 9).
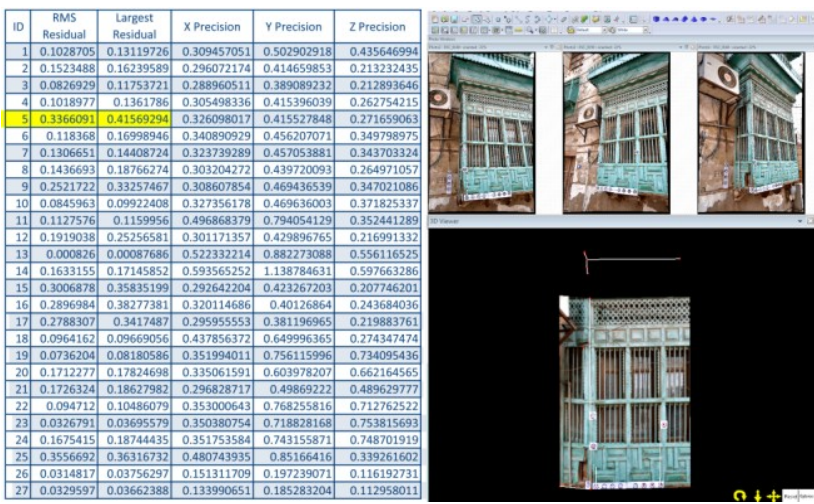

Figure 8.Table of RMS residual values in points-based project.

Furthermore the error compared to the actual measurement $(0.367 \mathrm{~mm})$ was deemed acceptable. From another aspect, in some ornamented details the models can be noisy, due to many reasons such as an inaccurate calibration process and picking the wrong radius value. To obtain more precise results, these problems must first be resolved.
For visualization and analysis, the texture map is strongly recommended. Images with good lighting and shadow conditions can offer this information and can be improved by using image editing applications that improve brightness and contrast and add depth to the map.

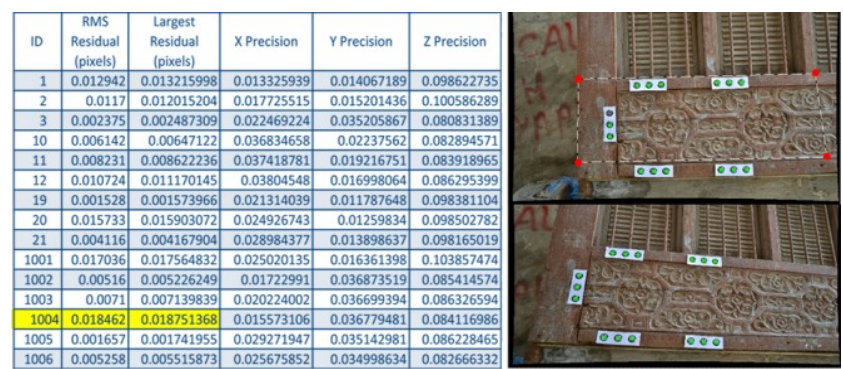

Figure 9. DSM project, table shows maximum residual error.

\section{CONCLUSION}

In this part of the investigation we have presented the application image-based 3D modelling approach, digital photogrammetry and DSM techniques by using photogrammetric and $3 \mathrm{D}$ modelling software $\left(\mathrm{PMS}^{\odot}\right.$ and Rhinoceros $^{\mathcal{C}}$ ) for the documentation of the Roshans elements which are considered the most important architectural heritage elements in Jeddah as well as the traditional architecture in Hejaz as a whole. In this paper, we have demonstrated that the stage of data acquisition is easy to process for the Roshans; few recommendations are needed and it does not require a high level of knowledge in photogrammetry.

The proposed methodology is presented in three steps for 3D reconstruction of the Roshans: first, main structural parts modelling by using photogrammetry; second, a complex ornamented details using DSM approach; and finally, the surface modelling and merging processes. These solutions are perfectly feasible, accurate, inexpensive, flexible and fast despite the logistical difficulties on site and the Roshans complexity, ornamental details and intricacies of location. The length of the entire process depends on the complexity of the Roshan. It takes 2-3 hours to create a complete model of a normal Roshan.

The results demonstrate the capability of close-range photogrammetry in accurate 3D modelling. The obtained precision in the $3 \mathrm{D}$ models corresponds perfectly which is required for any further work such as GIS, reconstruction using CAD/CAM technology, BIM and using Virtual Reality (VR) or Augmented Reality (AR) for visualization and educational purposes (Figure 10). To conclude the application and integration of different measurement and 3D modelling techniques are useful in effective cultural heritage preservation and documentation. 


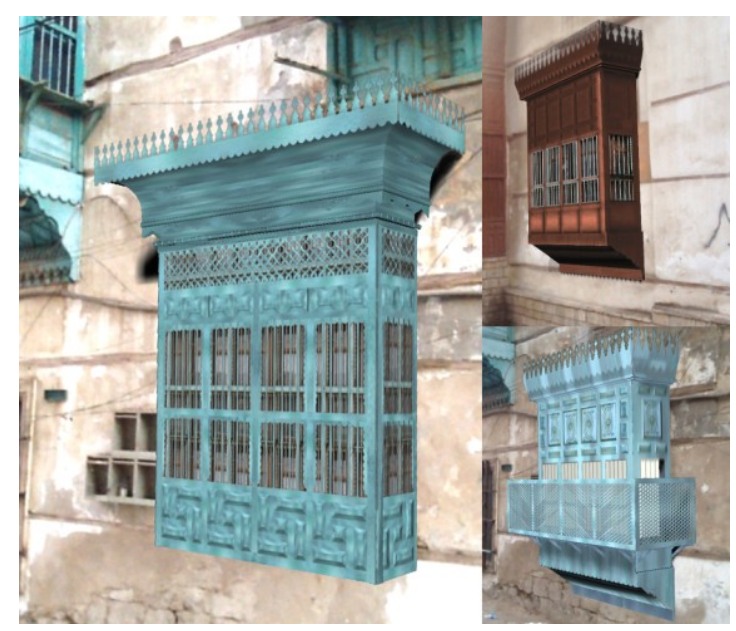

Figure 10.The Using of Augmented Reality (AR) technology.
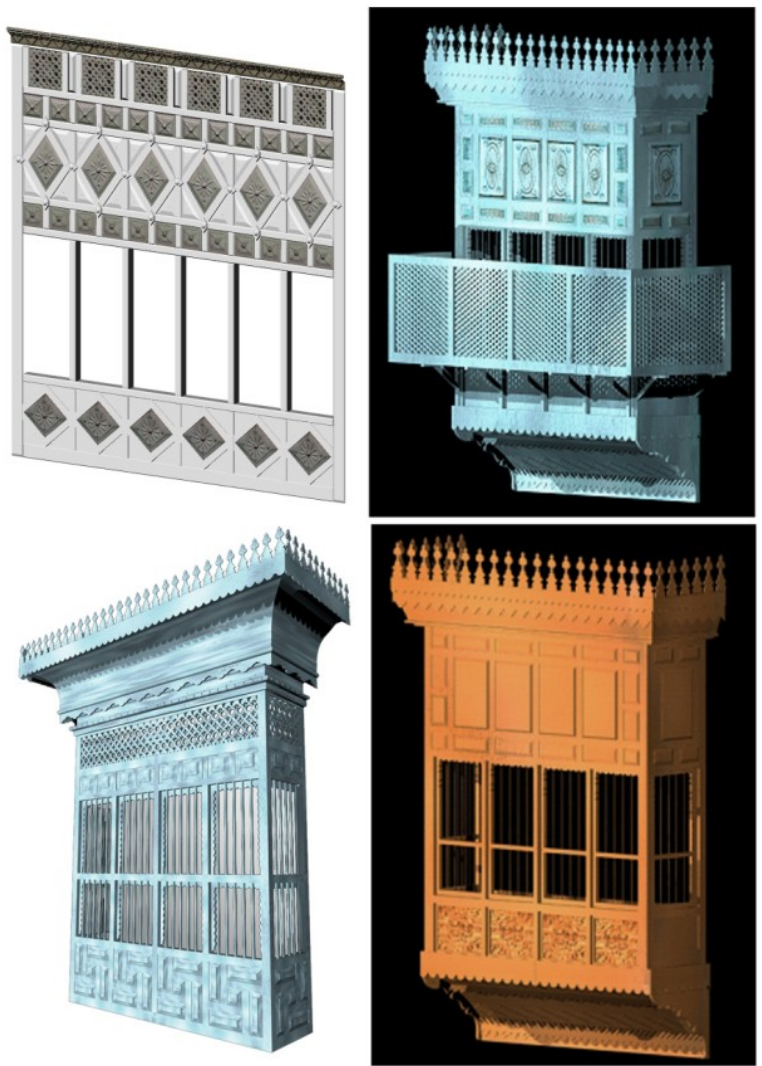

Figure 11.Final 3D textured models

\section{ACKNOWLEDGEMENTS}

We would like to thank:

-The Municipality of historical Jeddah, Saudi Arabia;

-Department of Architecture in the Faculty of Environmental Design in King Abdulaziz University (KAU), Jeddah, Saudi Arabia.

\section{REFERENCES}

\section{References from Books:}

Guidi, G., Remondino, F., 2012: 3D modeling from real data. In "Modeling and Simulation in Engineering", C. Alexandru (Ed.), ISBN 978-953-51-0012-6, DOI: 10.5772/30323, InTech Publisher (298 pages).

\section{References from Other Literature:}

Alby E., Smigiel E., Assali P., Grussenmeyer P. and Kauffmann-Smigiel I., 2009. Low Cost Solutions for Dense Point Clouds of Small Objects: Photomodeler Scanner vs. David Laserscanner. 22nd CIPA Symposium 2009, Kyoto, Japan.

Angawi, S.M., 1995 "The Roshan a Main Feature of the Hedjaz Architecture" Colored Glass and Mushrabiyyah in the Muslim World. Cario: Research Centre for IslamicHistory, Art and Culture, 1995.27-52.

Furukawa, Y., Ponce, J., 2007. Accurate, dense, and robust multi view stereopsis. In Proc. Int'l Conf. on Computer Vision and Pattern Recognition, IEEE, 2007, pp. 1-8.

Hirschmuller, H. (2008). Stereo processing by semi-global matching and mutual information. IEEE Trans. Patt. Anal. Mach. Intell., 30, 328-341.

Hullo, J.-F, Grussenmeyer, P., Fares, S., 2009. Photogrammetry and dense stereo matching approach applied the documentation of the cultural heritage of Kilwa (Saudi Arabia). 22nd CIPA Symposium 2009, Kyoto, Japan, 6p.

Jomah, H.A., 1992. The TraditionalProcess of Producing a House in Arabia During the 18th and 19th Centuries, A Case study of Hedjaz, Ph.D. Thesis,University of Edinburgh (unpublished).

Matthew, R.1972, Jeddah Master Plan Report, Existing Conditions Ministry of Interior (Municipal Affairs), Riyadh.

Remondino, F., Menna, F., 2008, Image-based surface measurement for close-range heritage documentation, The Int. Arch.of the Photogrammetry, Remote Sensing and Spatial Information Sciences, Beijing, Vol. XXXVII-B Part B5, pp. 199-206.

Remondino F., El-Hakim, S.: Image-based 3d modelling: a review. The Photogrammetric Record, 2006, 21(115): 269-291.

\section{References from websites:}

Eos Systems Inc. PhotoModeler software.

http://www.photomodeler.com/products/photomodeler.htm, (April 2012). 